\title{
Focal Cerebral Ischemia in Rats: Effect of Hemodilution with $\alpha-\alpha$ Cross-Linked Hemoglobin on Brain Injury and Edema
}

\author{
Daniel J. Cole, Randall M. Schell, John C. Drummond, Robert J. Pryzbelski \\ and Suzzane Marcantonio
}

\begin{abstract}
The effect of hemodilution, with $\alpha-\alpha$ cross-linked hemoglobin (DCLHb), on brain injury and edema was assessed after temporary middle cerebral artery occlusion in rats. Injury was analyzed with 2,3,5-triphenyltetrazolium chloride (TTC) stain and edema by microgravimety. Part A: DCLHb was given to maintain one of the following hematocrits (Hct) and normotension: 1) $45 / \mathrm{Hct}$, 2) $30 / \mathrm{Hct}$, 3) $16 / \mathrm{Hct}$, or 4$) 9 / \mathrm{Hct}$. Brain injury (\% of ischemic hemisphere, mean \pm SD) was less in the $30 /$ Hct group ( $31 \pm 4)$ versus the $45 / \mathrm{Hct}$ group $(42 \pm 5)$; and in the $16 / \mathrm{Hct}$ $(20 \pm 3)$ and $9 / \mathrm{Hct}(19 \pm 4)$ groups versus the $45 / \mathrm{Hct}$ and $30 / \mathrm{Hct}$ groups. Edema was less in the hemodiluted groups versus the $45 / \mathrm{Hct}$ group. Part B: DCLHb was given to maintain one of the following hematocrits and hyper (HTN) - or normotension (Norm): 1) 45/Norm, 2) 30/Norm, 3) 30/HTN, 4) 16/Norm, or 5) 16/HTN. In hematocrit matched groups hypertension decreased brain injury $(30 / \mathrm{HTN}-24 \pm 2<30$ /Norm $-34 \pm 4$; and 16/HTN $-17 \pm 3$ $<16 /$ Norm $-24 \pm 4$ ). Edema was not effected by hypertension. These results suggest that hemodilution with DCLHb decreases focal ischemic injury, and is most effective when given in a manner that induces hypertension.

RÉSUMÉ: Ischémie cérébrale focale chez le rat: effet de l'hémodilution par l'hémoglobine $\alpha-\alpha$ en liaison croisée sur le dommage cérébral et l'oedème. L'effet de l'hémodilution par l'hémoglobine $\alpha-\alpha$ en liaison croisée (DCLHb), sur le dommage cérébral et sur l'oedème a été évalué après occlusion temporaire de l'artère cérébrale moyenne chez le rat. Le dommage était analysé par coloration au TTC et l'oedème par microgravimétrie. Partie A: La DCLHb a été administrée pour maintenir les animaux normotendus (Norm) et l'hematocrite (Hct) comme suit: 1) $45 / \mathrm{Hct}, 2) 30 / \mathrm{Hct}, 3) 16 / \mathrm{Hct}$, ou 4) $9 / \mathrm{Hct}$. Le dommage cérébral (\% de l'hémisphere ischemique, moyenne \pm SD était moindre dans le groupe avec $30 / \mathrm{Hct}(31 \pm 4)$ comparé au groupe avec $45 / \mathrm{Hct}(42 \pm 5)$; et dans les groupes $16 / \mathrm{Hct}(20$ $\pm 3)$ et $9 / \mathrm{Hct}(19 \pm 4)$ comparés aux groupes $45 / \mathrm{Hct}$ et $30 / \mathrm{Hct}$. L'oedème était moindre dans les groupes hémodilués comparés au groupe $45 / \mathrm{Hct}$. Partie B: La DCLHb a été administrée pour maintenir les animaux hyper (HT) ou normotendus et l'hématocrite comme suit: 1) 45/Norm, 2) 30/Norm, 3) 30/HT, 4) 16/Norm, ou 5) 16/HT. Dans les groupes appariés pour l'Hct, l'hypertension diminuait le dommage cérébral (30/HTA - $24 \pm 2<30 / \mathrm{Norm}-34 \pm 4$; et 16/HTA $17 \pm 3<16 / \mathrm{Norm}-24 \pm 4$ ). L'oedème n'était pas modifié par l'hypertension. Ces résultats suggèrent qu'une hémodilution par la DCLHb diminue le dommage ischémique focal et est plus efficace quand elle est administrée de façon à induire une hypertension.
\end{abstract}

Can. J. Neurol. Sci. 1993: 20:30-36

Hemodilution has been proposed as a treatment of focal cerebral ischemia.' Hemodilution is postulated to increase ischemic cerebral blood flow (CBF) by either decreasing viscosity or via a direct cerebral vasodilatory response to decreased oxygen content and delivery. ${ }^{2-7}$

Although the rationale for employing hemodilution appears sound, the results of therapy have been inconsistent. ${ }^{8-15}$ Many explanations have been proposed for this inconsistency (e.g., magnitude of hematocrit reduction, treatment delay, or associated side effects). ${ }^{16,17}$ One hypothesis of merit is a limitation in oxygen transport when non-oxygen binding fluids are used such that any increase in oxygen delivery effected by hemodilutioninduced increases in CBF is counteracted by a concurrent decrease in oxygen carrying capacity. Although controversial, in terms of oxygen delivery to ischemic brain, it has been suggested that the optimal hematocrit when hemodiluting with a nonoxygen binding fluid is $30-35 \% .^{18}$ It is postulated that if hematocrit is $<30 \%$, although CBF may increase, oxygen delivery is reduced secondary to decreased oxygen carrying capacity.

In a previous study, we observed that hemodilution with $\alpha-\alpha$ cross-linked hemoglobin (DCLHb) decreased ischemia during middle cerebral artery occlusion (MACo) in rats. ${ }^{19}$ This effect

From the Departments of Anesthesiology, Loma Linda University, Loma Linda, California (D.J.C., R.M.S., R.J.P., S.M.), VA Medical Center. San Diego, California (J.C.D.), and University of California at San Diego, La Jolla, California (J.C.D.)

Received June 19, 1992. Accepted in final form October 14, 1992

Reprint request to: Daniel J. Cole, M.D., Department of Anesthesiology, Loma Linda University, Loma Linda, California, U.S.A. 92354 
was dose-dependent with the optimal effect on ischemic CBF being a hematocrit of $9 \%$. Accordingly, we evaluated the doserelated effect of hemodilution with $\mathrm{DCLHb}$ on histologic brain injury and edema during temporary MCAo in rats. In addition, we evaluated the effect of simultaneous hypertension (an inherent property of hemoglobin substitutes ${ }^{20}$ ) on ischemic brain injury.

\section{Materials AND METhOdS}

After approval by the institutional research committee, male, spontaneously hypertensive rats $(350-400 \mathrm{~g}, 16-20 \mathrm{wks})$ were anesthetized with isoflurane, orotracheally intubated and mechanically ventilated (Harvard, Boston, MA). The femoral vessels were cannulated for blood pressure monitoring (Full Scale Transducer/TA 2000 Recorder [Gould, Cerritos, CA]), blood sampling, and fluid administration. Cranial temperature was servo-controlled at $37^{\circ} \mathrm{C}$ with a heating blanket. Arterial blood $(125 \mu \mathrm{l}$ ) was analyzed (at $30-\mathrm{min}$ intervals) throughout MCAo and reperfusion, for $\mathrm{pH}, \mathrm{PaCO}_{2}, \mathrm{PaO}_{2}$, glucose, and hematocrit (IL-1306 $\mathrm{pH}$ Blood Gas Analyzer [Instrumentation Laboratory, Lexington, MA]; YSI Model 23-A Glucose Analyzer [Yellow Springs Instruments, Yellow Springs, $\mathrm{OH}$ ]; IEC MB Centrifuge Microhematocrit [DAMON/IEC Division, Needham Heights, MA]).

Each rat was randomized to one of the following groups for which blood volume was increased by $8.0 \mathrm{ml}(\approx 30 \%)$ and hematocrit (Hct) maintained at steady state throughout the study period. If DCLHb is initially given as an exchange transfusion normotension is maintained; however, if initially given as a rapid bolus mean arterial blood pressure $[\mathrm{MABP}]$ increases by $20-30 \mathrm{mmHg}$ for $\approx 180-\mathrm{min}$.

\section{Part A}

In this part DCLHb was given in order to maintain normotension.

$\mathbf{4 5} /$ Het $(\mathbf{n}=9)$. Blood volume was increased by giving $8.0 \mathrm{ml}$ of donor blood (hematocrit not manipulated).

30/Hct $(\mathbf{n}=9)$. Blood volume and hematocrit $(30 \%)$ were manipulated by a $5.0 \mathrm{ml}$ exchange transfusion with DCLHb, followed by an additional $8.0 \mathrm{ml}$ slow bolus (Baxter Healthcare Corporation; Deerfield, IL [Lot 2905T008]).

16/Hct $(n=9)$. Blood volume and hematocrit $(16 \%)$ were manipulated by a $15.0 \mathrm{ml}$ exchange transfusion with DCLHb, followed by an additional $8.0 \mathrm{ml}$ slow bolus.

9/Hct $(\mathbf{n}=9)$. Blood volume and hematocrit $(9 \%)$ were manipulated by a $20.0 \mathrm{ml}$ exchange transfusion with DCLHb, followed by an additional $8.0 \mathrm{ml}$ slow bolus.

\section{Part B}

In this part, different rats were used and DCLHb was administered in a regimen that maintains a $20-30 \mathrm{mmHg}$ increase in MABP during MCAo in the hypertensive groups (HTN); or DCLHb was administered as in Part $A$ for the normotensive groups (Norm).

45/Norm $(\mathbf{n}=9)$. Blood volume was increased by giving $8.0 \mathrm{ml}$ of donor blood (hematocrit not manipulated).

30/Norm $(\mathbf{n}=9)$. Blood volume and hematocrit $(30 \%)$ were manipulated by a $5.0 \mathrm{ml}$ exchange transfusion with DCLHb. followed by an additional $8.0 \mathrm{ml}$ slow bolus.

30/HTN ( $\mathbf{n}=9)$. Blood volume and hematocrit $(30 \%)$ were manipulated by an $8.0 \mathrm{ml}$ rapid bolus of DCLHb, followed by a $5.0 \mathrm{ml}$ exhange transfusion.
16/Norm $(n=9)$. Blood volume and hematocrit $(16 \%)$ were manipulated by a $15.0 \mathrm{ml}$ exchange transfusion with DCLHb, followed by an additional $8.0 \mathrm{ml}$ slow bolus.

16/HTN $(n=9)$. Blood volume and hematocrit $(16 \%)$ were manipulated by an $8.0 \mathrm{ml}$ rapid bolus of DCLHb, followed by a $15.0 \mathrm{ml}$ exchange transfusion.

Via a subtemporal craniectomy, MCAo was achieved with 10-0 monofilament nylon suture in two locations (proximal to the lenticulostriate branch and distal to the inferior cerebral vein) 10 achieve consistent ischemia to both cortical and sub-cortical tissue. ${ }^{15,16.19 .21}$ Following 180-min of MCAo the sutures were released and $120-\mathrm{min}$ of reperfusion allowed. During MCAo and reperfusion, the craniectomy site was bathed in mock cerebral spinal fluid $\left(37^{\circ} \mathrm{C}\right)$.

After MCAo and reperfusion, the brains were removed and sectioned in coronal planes 3.0 and $5.0 \mathrm{~mm}$ from the frontal pole (Figure 1). The middle segment was immersed in $2 \%$ TTC (2,3,5-triphenyltetrazolium chloride) at $37^{\circ} \mathrm{C}$ for $30-\mathrm{min}$. Each brain surface ( 3.0 and $5.0 \mathrm{~mm}$ coronal plane) was photographed with color slide film (Ektachrome, tungsten 160 ASA), and the area of brain injury (Figure 2) determined with a Drexel/ DUMAS Image Processing System. ${ }^{22.23}$ All image analysis was performed by an independent observer who was blinded to study protocol. Tissue was obtained for microgravimetry from the $1.0-3.0$ and $5.0-7.0 \mathrm{~mm}$ brain segments (Figure 1 ). Parallel specimens of cortex and basal ganglia were sampled from both hemispheres with a $2.0 \mathrm{~mm}$ biopsy punch (Baker and Cummins; Miami, FL). Specific gravity was measured by placing the tissue specimens in a kerosene-bromobenzene density gradient. The linear regression equation for each gradient was determined and verified with potassium sulfate standards. ${ }^{24}$

The DCLHb solution was prepared as follows. ${ }^{25}$ Outdated red blood cells (human) were lysed by exposure to hypertonic buffer. The hemolysate was centrifuged and stroma lipids removed. After ultrafiltration, the diaspirin compound bis $(3,5-$ dibromosalicyl) fumarate was used to cross-link molecular hemoglobin at the $\alpha$ chain. Viral contamination was eliminated and protein purification achieved by heat pasteurization. ${ }^{26.27}$ The DCLHb was diluted to a concentration of $\approx 10 \mathrm{~g} \cdot \mathrm{dL}^{-1}$ by adding electrolyte and buffer solution (Table 1 for lot release analysis). The solution was kept frozen $\left(-70^{\circ} \mathrm{C}\right)$ until needed for the current study when it was thawed to $5^{\circ} \mathrm{C}$, and on the day of the study passively warmed to room temperature and diluted to $7 \mathrm{~g} \cdot \mathrm{dL}^{-1}$ with lactated ringers to achieve the oncotic pressure of whole blood. Oxygen transport of DCLHb is similar to whole blood $^{25}$ (slight increase in oxygen unloading, Table 1). ${ }^{28}$ The $\alpha$ $\alpha$ cross-linking with bis(3,5-dibromosalicyl) fumarate stabilizes the solution and prolongs intravascular retention. ${ }^{29}$ The viscosity of DCLHb ( 1.4 centistokes) is comparable to serum albumin ${ }^{30}$ and considerably less than whole blood ( $>4.0$ centistokes). ${ }^{31}$

All between groups data was evaluated by an analysis of variance, and as appropriate mean values compared by t-tests with Scheffe's test for multiple comparisons. ${ }^{32} \mathrm{P}<0.05$ was considered significant.

\section{Results}

All data is presented as mean $\pm S D$. Except for expected differences in MABP and hematocrit, there were no differences in the physiologic data (Table 2). In the hemisphere contralateral to 


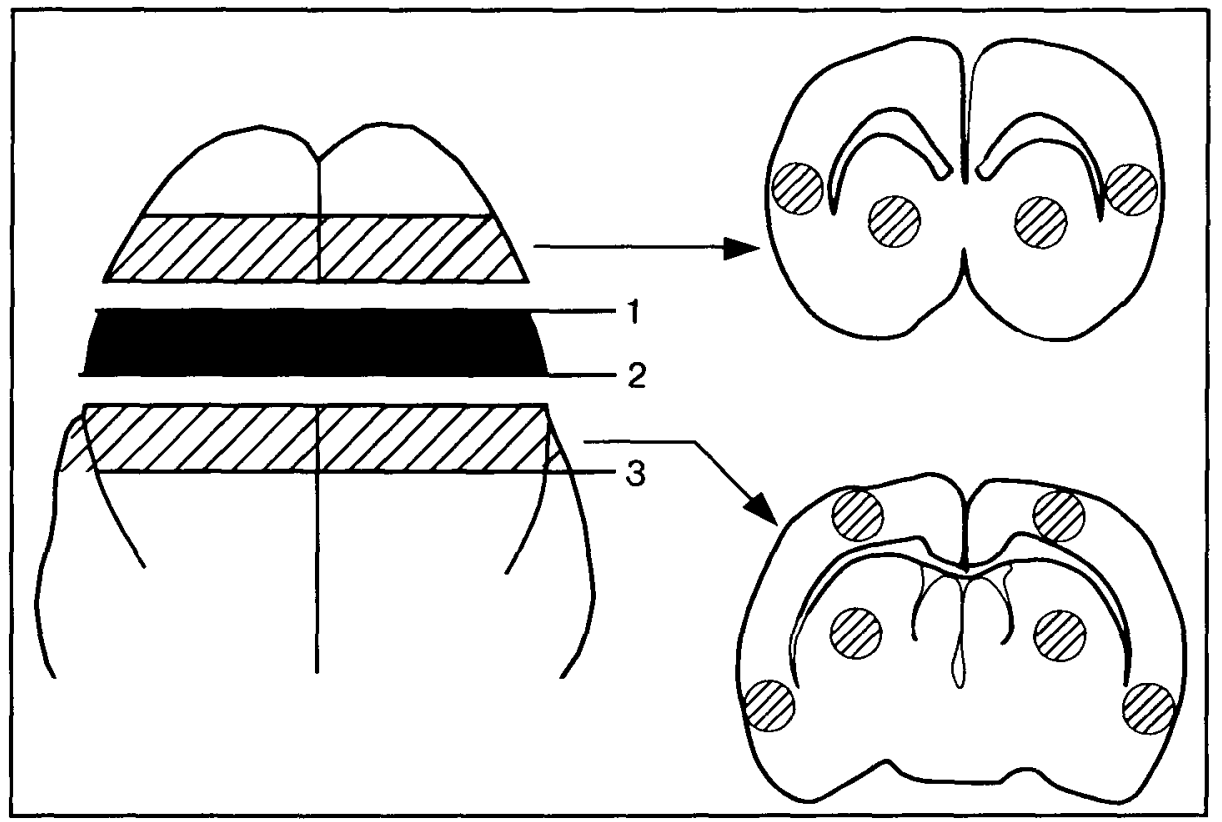

Figure 1 - Method of segmenting the brain, Left: segmenting of brain for analysis of injury (solid) and edema (hatched). 1 - the coronal plane $3.0 \mathrm{~mm}$ from the frontal pole. 2 - the coronal plane $5.0 \mathrm{~mm}$ from the frontal pole. 3 - the coronal plane $7.0 \mathrm{~mm}$ from the frontal pole. Right: specific areas of tissue sampling for microgravimetry. Top - is the posterior aspect of the $1.0-3.0 \mathrm{~mm}$ segment. Bottom - is the anterior aspect of the $5.0-7.0 \mathrm{~mm}$ segment.

MCAo there were no abnormalities in TTC staining. In general, specific gravity was greater in the hemisphere contralateral to MCAo versus the ischemic hemisphere. Brain injury was defined as the $\%$ of the cross-sectional area for the hemisphere ipsilateral to MCAo with deficient TTC staining (Figure 2).

\section{Part A}

Brain injury was less in the $16 / \mathrm{Hct}$ and $9 / \mathrm{Hct}$ groups versus the $30 / \mathrm{Hct}$ group; which was in turn less than the $45 / \mathrm{Hct}$ group (Table 3, p 0.05). As an example in section $1(3.0 \mathrm{~mm}$ from the frontal pole) brain injury was $42 \pm 5 \%$ in the $45 / \mathrm{Hct}$ group, $31 \pm 4 \%$ in the $30 / \mathrm{Hct}$ group, and $20 \pm 3 \%$ and $19 \pm 4 \%$ in the $16 / \mathrm{Hct}$ and $9 / \mathrm{Hct}$ groups respectively.

For all cortical areas in the ischemic hemisphere specific gravity was greater (decreased brain water) in the $16 / \mathrm{Hct}$ and $9 / \mathrm{Hct}$ groups versus the $45 / \mathrm{Hct}$ group; and for two cortical areas, specific gravity was greater in the $30 / \mathrm{Hct}$ group versus the $45 / \mathrm{Hct}$ group (Table, $p<0.05$ ). Specific gravity in the hemisphere contralateral to MCAo had a range of $1.043-1.046$ with a mean \pm SD of $1.045 \pm 0.001$.

\section{Part B}

There was an effect of hemodilution and hypertension on brain injury (Table 3 ). In the $3.0 \mathrm{~mm}$ section, for MABP matched groups, there was a dose-related effect of hemodilution on brain injury ( $45 /$ Norm $-44 \pm 4>30 /$ Norm $-34 \pm 4$ $>16 /$ Norm $-24 \pm 4, p<0.05$ ). In hematocrit matched groups hypertension decreased brain injury (30/HTN $-24 \pm 2$ $<30$ /Norm $-34 \pm 4$; and 16/HTN $-17 \pm 3<16$ /Norm $-24 \pm 4$, $\mathrm{p}<0.05$ ).

In general, hemodilution increased specific gravity. This effect was most prominent in the $16 \%$ hematocrit groups. Hypertension did not worsen brain edema (Table 4). Specific
Table 1: Chemical assay of $10 \% \alpha-\alpha$ cross-linked hemoglobin solution (DCLHb).

\begin{tabular}{lc}
\hline \hline Hemoglobin Content & $10.2 \mathrm{~g} \cdot \mathrm{dL}^{-1}$ \\
Methemoglobin & $0.7 \mathrm{~g} \cdot \mathrm{dL}^{-1}$ \\
$\mathrm{p} 50\left(37^{\circ} \mathrm{C}\right)$ & $32.0 \mathrm{mmHg}$ \\
Osmolality & $290 \mathrm{mOsm} \cdot \mathrm{Kg}^{-1}$ \\
Oncotic Pressure & $42.7 \mathrm{mmHg}$ \\
Viscosity & $1.3 \mathrm{centistokes}$ \\
$\mathrm{pH}$ & 7.50 \\
$\mathrm{Na}^{+}$ & $140 \mathrm{mEq} \cdot \mathrm{L}^{-1}$ \\
$\mathrm{~K}^{+}$ & $5.0 \mathrm{mEq} \cdot \mathrm{L}^{-1}$ \\
$\mathrm{Ca}^{++}$ & $2.2 \mathrm{mEq} \cdot \mathrm{L}^{-1}$ \\
$\mathrm{Mg}^{++}$ & $1.0 \mathrm{mEq} \cdot \mathrm{L}^{-1}$ \\
$\mathrm{Cl}^{-}$ & $115 \mathrm{mEq} \cdot \mathrm{L}^{-1}$ \\
Lactate & $30 \mathrm{mEq} \cdot \mathrm{L}^{-1}$ \\
\hline
\end{tabular}

gravity in the hemisphere contralateral to MCAo had a range of $1.043-1.046$ with a mean \pm SD of $1.045 \pm 0.001$.

\section{Discussion}

The results of this study indicate that hemodilution with DCLHb decreases brain injury and edema after temporary focal cerebral ischemia. In addition, if DCLHb is delivered in a manner which manifests an inherent hypertensive response further brain protection is conveyed. The TTC data imply that the beneficial effect of hemodilution on ischemic brain injury occurs in the border zone or penumbral area of the infarct (see Figure 2). Indeed, the decrease in brain injury effected by hemodilution in the present study corresponds to a similar brain region with a CBF of $11-20 \mathrm{ml} \cdot 100 \mathrm{~g}^{-1} \cdot \mathrm{min}^{-1}$ during MCAo. ${ }^{19}$ 


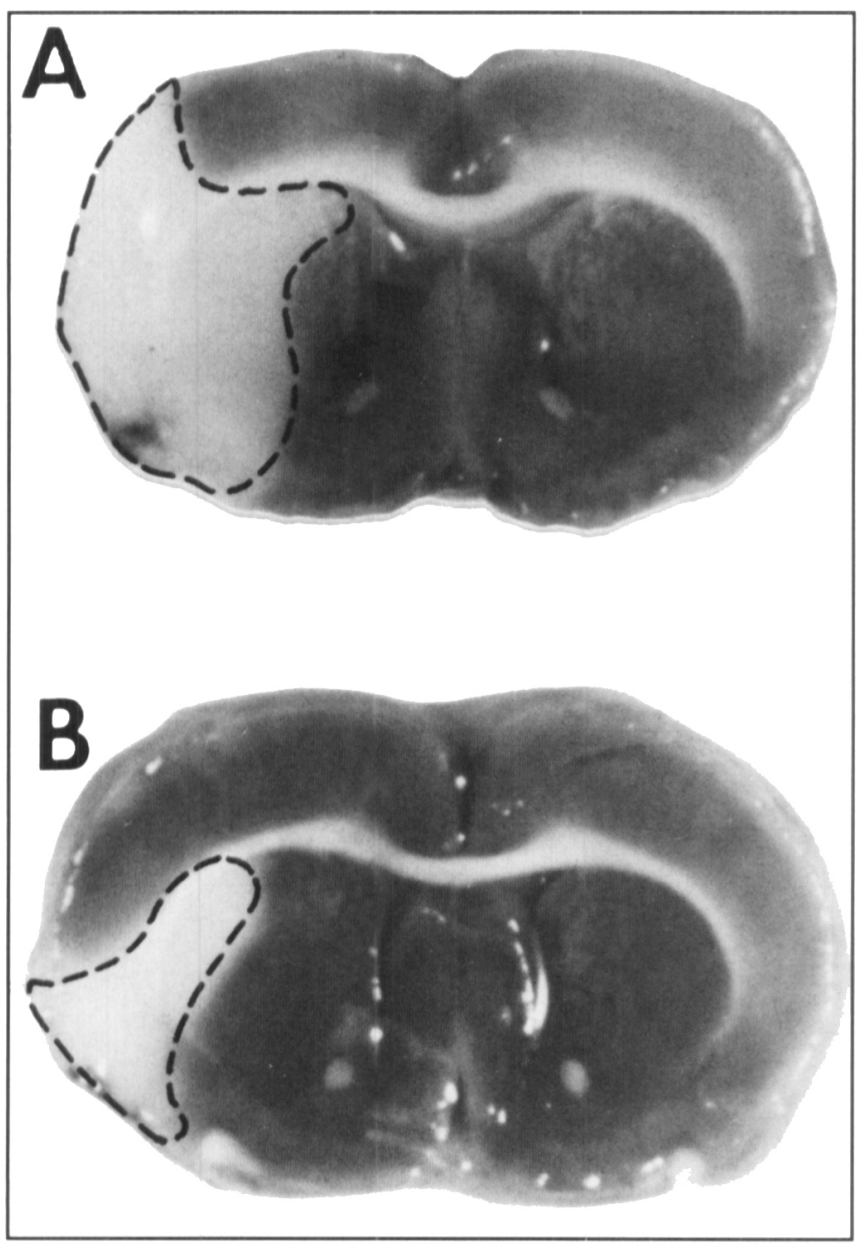

Figure 2 - 2,3.5-triphenyltetrazolium chloride (TTC) stained brain section (3.0 mm from the frontal pole) in the 45/Norm and $16 / \mathrm{HTN}$ groups for Part B. The dark area corresponds to normal brain, and the pale area within the dashed line was defined as injured brain.

Hemodilution is postulated to exert a favorable effect on CBF via two mechanisms; by decreasing viscosity ${ }^{2-4}$ or a direct myogenic/neurogenic induced vasodilatation in response to reduced oxygen content and delivery. ${ }^{5-7}$ The relative contribution of each mechanism may depend on whether hemodilution is employed in normal or ischemic brain. It is likely that both mechanisms are active in normal brain. Although myogenic/neurogenic induced vasodilatation may have a meaningful role in normal brain; it is plausible that during ischemia the vasculature responds differently. During ischemia the vasculature is in a state of vasoparalysis with areas of low flow or stasis. ${ }^{33.34}$ With low flow and low shear rates, any decrease in viscosity effects a greater increase in CBF than in normal brain. ${ }^{35,36}$ Moreover, it is difficult to conceive that with profound ischemia and maximum vasodilatation any reduction in oxygen content would induce further dilation. This concept is supported by recent data which demonstrate an atttenuation of vascular reactivity to hemodilution-induced reductions in oxygen content during ischemia. ${ }^{5}$ Other investigators have reported findings that support viscosity as the predominant mechanism of hemodilution-induced increases in CBF during ischemia..$^{37-40}$
A potential problem of our methodology was the hemodynamic effects of DCLHb. Although the mechanism is not clear, hemoglobin substitutes are known to increase blood pressure. ${ }^{20}$ In an identical model of cerebral ischemia we demonstrated a favorable effect of hypertension on ischemic injury. 15 Accordingly, it was anticipated that if DCLHb was administered in its customary regimen (a rapid bolus with accompanying hypertension) we would not be able to discern if a change in brain injury was due to hemodilution or hypertension. Thus, a method of giving DCLHb without hypertension was required. The solution was surprisingly simple. We observed that if DCLHb was initially administered as an exchange transfusion there was neither an immediate change in MABP nor a change during subsequent administration (without exchange transfusion). However, if DCLHb was given as a rapid bolus MABP increased by $20-30 \mathrm{mmHg}$ for three hours. (During the third hour MABP gradually decreased but it was still above baseline by $15-20 \mathrm{mmHg}$.) The increase in MABP did not extend into reperfusion. In this model, at reperfusion, there is an immediate and transient decrease in MABP which abolished any lingering affect of DCLHb on blood pressure. Albeit, there were no differences between study groups during any 15-min increment of reperfusion. Accordingly, for simplicity of presentation the physiologic data was consolidated over the entire MCAO and reperfusion period.

A limitation of this study is TTC stain. During normal acrobic metabolism TTC is converted by mitochondrial oxidative enzymes to a formazan product which stains the brain red. However, ischemia renders these oxidative enzyme systems dysfunctional, and by effecting a failure of TTC conversion to its red derivative a pale area of brain results (Figure 2). Although the delineation of normal from abnormal brain is clear, the interpretation of the pale area as absolutely infarcted is suspect. A portion of the pale area is most certainly infarcted, however some of the pale area may have a potential for neuronal recovery. 22 Nonetheless, the goal of this study was to analyze histologically the immediate effects of treatment after a short period of temporary focal cerebral ischemia. Accordingly. TTC stain was chosen in order to avoid extending the reperfusion period beyond 120-min (a necessary delay with conventional microscopy); which would have provoked additional brain injury and obscured the immediate effect of treatment on brain injury.

An additional limitation was that we measured area, and not volume, of ischemic brain injury. An assessment of volume would have provided data on the fronto-caudal extent of ischemic brain injury which is the current standard in our laboratory. However, such an evaluation would have precluded microgravimetric determination of cerebral edema in the same animal. As hypervolemia, hypertension, and extreme levels of hemodilution were induced, we were concerned that such therapy might convey a risk of cerebral edema. Accordingly, we considered it important to assess the risk of cerebral edema in the present study. We acknowledge that an analysis of the fronto-caudal extent of ischemic brain injury would have been ideal if we were not concerned about cerebral edema.

A previous study, in a similar model of focal cercbral ischemia, demonstrated a dose-dependent effect of hemodilution with DCLHb on ischemic CBF (the maximum decrease in ischemia observed at a hematocrit of $9 \%$ ). ${ }^{19}$ The purpose of the 
Table 2: Physiologic data (mean \pm SD) during MCAo and reperfusion for Part $A$ and $B$.

\begin{tabular}{lcccc}
\hline \hline Part A & $\mathbf{4 5} / \mathbf{H c t}$ & $\mathbf{3 0} / \mathbf{H c t}$ & $\mathbf{1 6 / H c t}$ & $\mathbf{9 / H c t}$ \\
\hline $\mathbf{p H}$ & $7.40 \pm 0.02$ & $7.42 \pm 0.03$ & $7.43 \pm 0.03$ & $7.43 \pm 0.03$ \\
$\mathbf{P a O}_{2}(\mathrm{mmHg})$ & $146 \pm 18$ & $140 \pm 11$ & $149 \pm 15$ & $135 \pm 19$ \\
$\mathbf{P a C O}_{2}(\mathrm{mmHg})$ & $37.8 \pm 1.4$ & $37.2 \pm 1.2$ & $37.0 \pm 0.9$ & $37.3 \pm 1.1$ \\
$\mathbf{M A B P}(\mathrm{mmHg})$ & $133 \pm 7$ & $136 \pm 8$ & $136 \pm 13$ & $137 \pm 11$ \\
Hematocrit $(\%)$ & $46 \pm 1^{*}$ & $30 \pm 1^{*}$ & $16 \pm 1^{*}$ & $9 \pm 1^{*}$ \\
Glucose $\left(\mathrm{mg} \cdot \mathrm{dl}^{-1}\right)$ & $114 \pm 13$ & $125 \pm 21$ & $126 \pm 19$ & $119 \pm 14$ \\
\hline
\end{tabular}

* $p<0.05$ versus the other three groups.

\begin{tabular}{lccccc}
\hline Part B & 45/Norm & 30/Norm & 30/HTN & 16/Norm & 9/HTN \\
\hline pH & $7.41 \pm 0.02$ & $7.42 \pm 0.02$ & $7.42 \pm 0.03$ & $7.43 \pm 0.03$ & $7.43 \pm 0.03$ \\
PaO $_{2}(\mathrm{mmHg})$ & $142 \pm 18$ & $137 \pm 14$ & $133 \pm 15$ & $137 \pm 17$ & $144 \pm 19$ \\
$\mathbf{P a C O}_{2}(\mathrm{mmHg})$ & $38.1 \pm 1.0$ & $37.7 \pm 0.9$ & $37.5 \pm 1.1$ & $37.2 \pm 1.4$ & $37.6 \pm 1.2$ \\
$\mathbf{M A B P}(\mathrm{mmHg})$ & $136 \pm 5$ & $134 \pm 9$ & $151 \pm 8^{+}$ & $133 \pm 9$ & $152 \pm 11^{*}$ \\
Hematocrit $(\%)$ & $45 \pm 1$ & $30 \pm 1^{+}$ & $30 \pm 1^{+}$ & $16 \pm 1^{++}$ & $16 \pm 1^{++}$ \\
Glucose $\left(\mathrm{mg} \cdot \mathrm{dl}^{-1}\right)$ & $108 \pm 10$ & $113 \pm 11$ & $110 \pm 9$ & $115 \pm 17$ & $111 \pm 10$ \\
\hline
\end{tabular}

"p $<0.05$ versus the $45 /$ Norm, $30 /$ Norm, and 16/Norm groups.

${ }^{*} p<0.05$ versus the $45 /$ Norm group.

${ }^{t+} \mathrm{p}<0.05$ versus the $45 / \mathrm{Norm}, 30 / \mathrm{Norm}$, and $30 / \mathrm{HTN}$ group.

$\mathrm{pH}, \mathrm{PaCO}_{2}, \mathrm{PaO}_{2}$, hematocrit, and glucose were collected at 30-min increments throughout MCAo and reperfusion, and MABP was monitored continuously and collected in 15-min time increments. See text for definition of group abbreviations.

Table 3: Area of ischemic injury (mean \pm SD) for Part $A$ and $B$.

\begin{tabular}{lllll}
\hline \hline Part A & 45/Hct & 30/Hct & 16/Hct & 9/Hct \\
\hline 3.0 mm section & $42 \pm 5$ & $31 \pm 4^{*}$ & $20 \pm 3^{+}$ & $19 \pm 4^{*}$ \\
5.0 mm section & $42 \pm 4$ & $33 \pm 3$ & $22 \pm 5^{+}$ & $20 \pm 5^{+}$ \\
\hline
\end{tabular}

" $p<0.05$ versus the $45 / \mathrm{Hct}$ group.

${ }^{+} \mathrm{p}<0.05$ versus the $45 / \mathrm{Hct}$ and $30 / \mathrm{Hct}$ groups.

\begin{tabular}{lccccc}
\hline Part B & 45/Norm & 30/Norm & 30/HTN & 16/Norm & 9/HTN \\
\hline 3.0 mm section & $44 \pm 4$ & $34 \pm 4^{*}$ & $24 \pm 2^{+}$ & $24 \pm 4^{+}$ & $17 \pm 3^{++}$ \\
5.0 mm section & $41 \pm 5$ & $36 \pm 4$ & $27 \pm 4^{+}$ & $26 \pm 3^{+}$ & $19 \pm 3^{++}$ \\
\hline
\end{tabular}

" $p<0.05$ versus the $45 /$ Norm group.

${ }^{+} \mathrm{p}<0.05$ versus the $45 /$ Norm and $30 /$ Norm groups.

${ }^{t+} \mathrm{p}<0.05$ versus the other four groups.

Ischemic injury was defined as the \% of the cross-sectional area for the hemisphere ipsilateral to MCAo that failed to stain with TTC in coronal brain slices 3.0 and $5.0 \mathrm{~mm}$ posterior to the frontal pole (Figure 2).

present study was to evaluate if this decrease in ischemia would translate to a histologic end-point (which was the rationale for including a $9 \%$ and $16 \%$ hemodilution group in Part $\mathrm{A}$ ). However, as no decrease in brain injury was established in the $9 / \mathrm{Hcl}$ group versus the $16 / \mathrm{Hct}$ group, a $9 \%$ group was not included in Part B. Although not measured in the present study, previous work ${ }^{19}$ indicated a dose-dependent effect of DCLHb on oxygen delivery to the ischemic hemisphere (without hypertension). Oxygen delivery increased by $\approx 50 \%$ in rats which were hemodiluted to a hematocrit of $9 \%$ versus the control state. No data is available on oxygen delivery during hypertension (it is likely to be increased in a pressure passive vasculature ${ }^{41}$ ).

Although the use of hemodilution in laboratory studies has had success, clinical trials have produced inconsistent results. ${ }^{8-15}$ Several explanations may account for this inconsistency. The first is the likelihood of a window of treatment following the onset of ischemia after which therapeutic maneuvers that augment $C B F$ are not effective in limiting injury. ${ }^{12}$ If therapy is instituted after this window, ischemic injury may have progressed beyond the point of efficacy at which time only 


\begin{tabular}{|c|c|c|c|c|}
\hline Part A & 45/Hct & $30 / \mathrm{Het}$ & $16 / \mathrm{Het}$ & 9/Hct \\
\hline \multicolumn{5}{|c|}{ Section 1} \\
\hline Cortex & $1.035 \pm 0.003$ & $1.036 \pm 0.002$ & $1.040 \pm 0.002^{*}$ & $1.041 \pm 0.002^{\circ}$ \\
\hline Basal Ganglia & $1.043 \pm 0.001$ & $1.044 \pm 0.002$ & $1.043 \pm 0.001$ & $1.044 \pm 0.002$ \\
\hline \multicolumn{5}{|c|}{ Section 2} \\
\hline Cortex (superior) & $1.035 \pm 0.002$ & $1.042 \pm 0.003^{\dagger}$ & $1.043 \pm 0.002^{\dagger}$ & $1.044 \pm 0.002^{\dagger}$ \\
\hline Cortex (inferior) & $1.032 \pm 0.003$ & $1.038 \pm 0.002^{+}$ & $1.040 \pm 0.002^{\dagger}$ & $1.039 \pm 0.002^{+}$ \\
\hline Basal Ganglia & $1.043 \pm 0.002$ & $1.042 \pm 0.002$ & $1.043 \pm 0.001$ & $1.043 \pm 0.002$ \\
\hline
\end{tabular}

* $\mathrm{p}<0.05$ versus the $45 / \mathrm{Hct}$ and $30 / \mathrm{Hct}$ groups.

${ }^{+} \mathrm{p}<0.05$ versus the $45 / \mathrm{Hct}$ group.

\begin{tabular}{lccccc}
\hline Part B & 45/Norm & 30/Norm & 30/HTN & 16/Norm & 16/HTN \\
\hline \multicolumn{5}{c}{ Section 1 } \\
Cortex & $1.036 \pm 0.002$ & $1.035 \pm 0.002$ & $1.038 \pm 0.002$ & $1.040 \pm 0.002^{*}$ & $1.040 \pm 0.002^{*}$ \\
Basal Ganglia & $1.045 \pm 0.003$ & $1.045 \pm 0.003$ & $1.044 \pm 0.001$ & $1.044 \pm 0.002$ & $1.045 \pm 0.003$ \\
& \multicolumn{7}{c}{ Section 2 } \\
Cortex (superior) & $1.035 \pm 0.002$ & $1.043 \pm 0.002^{\dagger}$ & $1.045 \pm 0.002^{\dagger}$ & $1.045 \pm 0.002^{+}$ & $1.044 \pm 0.002^{+}$ \\
Cortex (inferior) & $1.034 \pm 0.002$ & $1.036 \pm 0.003$ & $1.039 \pm 0.002^{\dagger}$ & $1.039 \pm 0.002^{+}$ & $1.041 \pm 0.002^{+}$ \\
Basal Ganglia & $1.043 \pm 0.001$ & $1.044 \pm 0.002$ & $1.045 \pm 0.002$ & $1.044 \pm 0.002$ & $1.044 \pm 0.002$ \\
\hline
\end{tabular}

" $p<0.05$ versus the $45 /$ Norm and $30 /$ Norm groups.

${ }^{+} \mathrm{p}<0.05$ versus the $45 /$ Norm group.

Section 1 was tissue $1.0-0.3 \mathrm{~mm}$ from the frontal pole, and Section 2 was tissue $5.0-7.0 \mathrm{~mm}$ from the frontal pole (Figure 1).

detrimental side-effects of therapy are manifested. ${ }^{16.17}$ In contrast, if hemodilution is instituted before or shortly after the onset of ischemia a positive outcome may be more likely. In the present study hemodilution was instituted prior to ischemia, maximizing the efficacy of therapy but limiting model relevance to circumstances in which hemodilution can be employed prophylactically (situations that convey a predictable risk of ischemia [e.g., carotid endarterectomy, occlusion of a cerebral artery during aneurysm surgery]). The second issue concerns potential adjunctive effects of hypervolemia. When hypervolemia and hemodilution are currently employed, hypervolemia may counter decreases in perfusion pressure associated with isovolemic hemodilution. ${ }^{9} .11$ In addition, hypervolemia should be therapeutic for dehydration/hypovolemic conditions which have been implicated as exacerbating ischemia in a subpopulation of stroke patients. ${ }^{42}$ And finally, is the issue of decreased oxygen content when using non-oxygen binding fluids for hemodilution. Such fluids place inherent limits on oxygen transport, and therefore the effectiveness and magnitude of therapy. ${ }^{18}$ In theory, hemodilution with oxygen-binding fluids may convey a unique advantage in the treatment of temporary focal cerebral ischemia.

In summary, the effect of hypervolemic-hemodilution with a hemoglobin solution during temporary focal cerebral ischemia was determined. The results support the hypothesis that hemodilution with $\alpha-\alpha$ cross-linked hemoglobin effects a decrease in brain injury and edema. In addition, if DCLHb is delivered in a manner which manifests an inherent hypertensive response further brain protection is afforded. The therapeutic benefit of the present treatment modality must be addressed in terms of functional outcome in a higher species before a more definitive statement can be made.

\section{ACKNOWLEDGEMENT}

The authors gratefully acknowledge the technical assistance of Terrill Osborne.

\section{REFERENCES}

1. Heros RC, Korosue K. Hemodilution for cerebral ischemia. Stroke 1989; 20: 423-427.

2. Paulson OB, Parving H-H, Olesen J, Skinhøj E. Influence of carbon monoxide and of hemodilution on cerebral blood flow and blood gases in man. J Appl Physiol 1973; 35: 111-116.

3. Häggendal E, Nilsson NJ, Norbäck B. Effect of blood corpuscle concentration on cerebral blood flow. Acta Chir Scand Suppl $1966 ; 364: 3-12$.

4. Häggendal E, Norbäck B. Effect of viscosity on cerebral flood flow. Acta Chir Scand Suppl 1966; 364: 13-22.

5. Back $T$, von Kummer $R$. Oxygen reactivity of cerebral circulation determined in cats. J Cereb Blood Flow Metab 1991; 11: S458.

6. von Kummer R, Scharf J, Back T, et al. Autoregulatory capacity and the effect of isovolemic hemodilution on local cerebral blood flow. Stroke 1988; 19: 594-597.

7. Brown MM, Wade JPH, Marshall J. Fundamental importance of arterial oxygen content in the regulation of cerebral blood flow in man. Brain 1985; 108: 81-93.

8. Wood JH, Simeone FA, Fink EA, Golden MA. Hypervolemic hemodilution in experimental focal cerebral ischemia. J Neurosurg 1983; 59: 500-509.

9. Tu YK, Heros RC, Karacostas D, et al. Isovolemic hemodilution in experimental focal cerebral ischemia. Part 2. Effect on regional cerebral blood flow and size of infarction. J Neurosurg 1988; 69: $82-91$. 
10. Italian Acute Stroke Study Group. Haemodilution in acute stroke: results of the Italian haemodilution trial. Lancet 1988; 8581: 318-321.

11. Scandinavian Stroke Study Group. Multicenter trial of hemodilution in acute ischemic stroke. Stroke 1988; 19: 464-471.

12. The Hemodilution in Stroke Study Group. Hypervolemic hemodilution treatment of acute stroke. Stroke 1989; 20: 317-323.

13. Asplund K. Randomized clinical trials of hemodilution in acute ischemic stroke. Acta Neurol Scand 1989; 127: 22-30.

14. Koller M, Haenny P, Hess K, et al. Adjusted hypervolemic hemodilution in acute stroke. Stroke 1990; 21: 1429-1434.

15. Cole DJ, Drummond JC, Osborne TN, Matsumura J. Hypertension and hemodilution during cerebral ischemia reduce brain injury and edema. Am J Physiol 1990; 259: H211-H217.

16. Cole DJ, Drummond JC, Ruta TS, Peckham NH. Hemodilution and hypertension effects on cerebral hemorrhage in cerebral ischemia in rats. Stroke 1990; 21: 1333-1339.

17. Cole DJ, Drummond JC, Matsumura JS, Marcantonio S, Chi-Lum B1. Hemodilution and hypertension during temporary middle cerebral artery occlusion in rats: the effect on blood-brain barrier permeability. Can J Neurol Sci 1990; 17: 372-377.

18. Kee DB, Jr., Wood JH. Influence of blood rheology on cerebral circulation. In: Wood JH, ed. Cerebral Blood Flow-Physiologic and Clinical Aspects. New York: McGraw-Hill, 178-181.

19. Cole DJ, Schell RM, Pryzbelski RJ, et al. Focal cerebral ischemia in rats: effect of hemodilution with $\alpha-\alpha$ cross-linked hemoglobin on CBF. J Cereb Blood Flow Metab 1992; 12: 971-976.

20. Rabinovici R, Rudolph AS, Feuerstein G. Characterization of hemodynamic, hematologic, and biochemical responses to administration of liposome-encapsulated hemoglobin in the conscious, freely moving rat. Circ Shock 1989; 29: 115-132.

21. Duverger D, Mackenzie ET. The quantification of cerebral infarction following focal ischemia in the rat: influence of strain, arterial pressure, blood glucose concentration, and age. J Cereb Blood Flow Metab 1988; 8: 449-461.

22. Cole DJ, Drummond JC, Ghazal EA, Shapiro HM. A reversible component of cerebral injury as identified by the histochemical stain 2,3,5-triphenyltetrazolium chloride (TTC). Acta Neuropathol 1990; 80: 152-155.

23. Bederson JB, Pitts LH, Germano SM, et al. Evaluation of 2,3,5triphenylotetrazolium chloride as a stain for detection and quantification of experimental cerebral infarction in rats. Stroke 1986; 17: 1304-1308

24. Netson SR, Mantz ML, Maxwell JA. Use of specific gravity in the measurement of cerebral edema. J Appl Physiol 1971; 30: 268271.

25. Chatterjee R, Welty EV, Walder RY, et al. Isolation and characterization of a new hemoglobin derivative cross-linked between $\alpha$ chains (lysine $99 \alpha_{1} \rightarrow$ lysine $99 \alpha_{2}$ ). J Biol Chem 1986; 261: 9929-9937.

26. Estep TN, Bechtel MK, Miller TJ, Bagdasarian A. Virus inactivation in hemoglobin solutions by heat. In: Change TMS, Geyer
RP, eds. Blood Substitutes. New York: Marcel Dekker, 1989; 129-134.

27. Estep TN, Bechtel MK, Bush SL, et al. The purification of hemoglobin solutions by heating. Prog Clin Biol Res 1989; 319: 325-336.

28. Vandergriff KD, Medina F, Marini MA, Winslow RM. Equilibrium oxygen binding to $\alpha \alpha$-cross-linked human hemoglobin. J Biol Chem 1989; 264: 17824-17833.

29. Hess JR, Fadare SO, Tolentino LSL, Bangal NR. The intravascular persistence of DBBF-hemoglobin. In: Brewer G. Progress in Clinical and Biological Research (Red Cell: $7^{\text {th }}$ Ann Arbor Conference). New York: Alan R. Liss, 1989; 319: 351-360.

30. Usami S, Chien S, Gregersen Ml. Hemoglobin solution as a plasma expander: effects on blood viscosity. Proc Soc Exp Biol Med 1971; 136: 1232-1235.

31. DeVenuto F, Busse KR, Zegna AI. Viscosity of human blood hemodiluted with crystalline hemoglobin solution. Transfusion 1981; 21: 752-756.

32. Wilkinson L. Multivariate general linear hypothesis. $n$ : SYSTAT The System for Statistics. Evanston, IL: SYSTAT, Inc., 1987; 22-30.

33. Hartmann A, Dettmers C, Beyenburg S. Effect of hemodilution on regional cerebral blood flow. Acta Neurol Scand 1989; 127: 3648.

34. Symon L, Lassen NA, Astrup J. Thresholds of ischemia in brain cortex. Adv Exp Med Biol 1977; 94: 775-782.

35. Harrison MJG. Influence of haematocrit in the cerebral circulation. Cerebrovasc Brain Metab Rev 1989; 1: 55-67.

36. Mirhashemi S, Ertefai S, Messmer K, Intaglietta M. Model analysis of the enhancement of tissue oxygenation by hemodilution due to increased microvascular flow velocity. Microvas Res 1987; 34: $290-301$

37. Korosue K, Heros RC. Mechanism of incerebral blood flow augmentation by hemodilution in rabbits. Stroke 1992; 23: 1487 1493.

38. Hartmann A, Rommel T, Dettmers $C$, et al. Hemodilution in cerebral infarcts. Arzneim-Forsch/Drug Res 1991; 41: 348-351.

39. Muizelaar JP, Wei EP, Kontos HA, Becker DP. Cerebral blood flow is regulated by changes in blood pressure and in blood viscosity alike. Stroke 1986; 17: 44-48.

40. Muizelaar JP, Bouma GJ, Levasseur JE, Kontos HA. Effect of hematocrit variations on cerebral blood flow and basilar artery diameter in vivo. Am J Physiol 1992; 262: H949-H954.

41. Drummond JC, Oh YS, Cole DJ, Shapiro HM. Phenylephrineinduced hypertension reduced ischemia following middle cerebral artery occlusion in rats. Stroke $1989 ; 20: 1538-1544$.

42. Goslinga H, Eijzenbach V, Heuvelmans JH, et al. Custom-tailored hemodilution with albumin and crystalloids in acute ischemic stroke. Stroke 1992; 23: 181-188. 